\title{
Language Use Across International Contexts: Shaping the Minds of L2 Speakers
}

\author{
JUDITH F. KROLL \\ University of California, Riverside \\ judith.kroll@ucr.edu \\ PaOla E. Dussias \\ Pennsylvania State University \\ pdussias@psu.edu \\ MARÍA TERESA BAJO \\ University of Granada \\ mbajo@ugr.es
}

\section{ABSTRACT}

\begin{abstract}
Bilingualism is a complex life experience. Second language (L2) learning and bilingualism take place in many different contexts. To develop a comprehensive account of dual-language experience requires research that examines individuals who are learning and using two languages in both the first language (L1) and second language (L2) environments. In this article, we review studies that exploit the presence of an international research network on bilingualism to investigate the role of the environment and some the unique characteristics of L2 learning and bilingual language usage in different locations. We ask how the context of learning affects the acquisition of the L2 and the ability to control the use of each language, how language processing is changed by the patterns of language usage in different places (e.g., whether bilinguals have been immersed in the L2 environment for an extended period of time or whether they code-switch), and how the bilingualism of the community itself influences learning and language use.
\end{abstract}

Forms of language use across international contexts shape the minds of second language (L2) speakers. In much of the research on L2 learning and bilingualism, there has been a focus on how individuals might achieve a high level of proficiency in each of the languages that they speak. For adults, in particular, the issue of whether there are constraints that might impede or facilitate learning an L2 has shaped the field. Traditional accounts of language learning assumed that early in life there is openness to language input and exposure, but that beyond early childhood, there is a narrowing of sensitivity that requires alternative means to achieve proficiency (e.g., Clahsen \& Felser, 2006; Johnson \& Newport, 1989; Lenneberg, 1967; Piske, MacKay, \& Flege, 2001). In the last two decades, the traditional account has been revised. In part, the assumption of hard constraints on adult language learning has been challenged by recent studies that exploit the tools of neuroscience to demonstrate widespread plasticity in learning across the life 
span (e.g., Bialystok \& Kroll, in press; Caffarra, Molinaro, Davidson, \& Carreiras, 2015; Roncaglia-Denissen \& Kotz, 2016; Steinhauer, 2014;). It is beyond the scope of this article to fully review this literature, but for the present purposes there are two important observations. The first is that there is evidence that even late learners are able to acquire subtle aspects of the L2 grammar. The second is that the native language, even for monolingual speakers, is variable across speakers and contexts (e.g., Pakulak \& Neville, 2010). The apparent openness of the language system suggests that the model of an ideal native speaker requires revision.

Highly proficient bilinguals are not monolingual, as native speakers are, in either of the two languages they speak (Grosjean, 1989). There is a constant interplay between the bilingual's two languages that shapes not only the L2 but also the native or first language (L1). The two languages change in response to the way in which they interact. Those changes are mediated not only by the contexts in which language is learned and used but also by the requirements to draw on cognitive resources to enable bilingual performance.

A consequence of this new view of L2 learning and bilingualism is that the factors that characterize the environment and the nature of language input become more important. In this article we provide a brief overview to this approach to L2 learning and bilingualism. Our goal is to highlight both the scope and dynamics of language learning and use. We have collaborated for more than a decade to investigate language processing and the cognitive and neural mechanisms that support it. We have come to see that a focus on international collaboration ${ }^{1}$ that enables the same questions to be asked in different locations creates an ideal vantage point from which it becomes possible to tease apart the roles of context and experience. Bilingualism is a complex phenomenon that takes different forms in different places and among speakers of different languages (for a discussion of how bilingualism reflects language variation, see Fricke, Zirnstein, Navarro-Torres, $\&$ Kroll, in press). Only by taking a comparative approach that examines language experience across contexts will it become possible to develop a comprehensive account of language learning and bilingualism. Language immersion thus becomes a central focus. It not only provides a vehicle for enhancing adult language learning, something that has long been touted as a reason for study abroad and travel, but also becomes the very foundation on which hypotheses about bilingualism can be tested, because it potentially reveals the way that speakers negotiate the competition across the two languages.

In what follows we illustrate this approach. We first review recent studies of language learning and language processing under distinct conditions of immersion. Notably, we show that not only does the context of language use affect the availability of information in each language, but it also modulates the demands made on bilingual speakers and listeners to regulate the two languages. We then consider two aspects of language processing that are uniquely bilingual and that also reflect language regulation and cognitive control. One is code-switching, the ability of bilinguals to move in and out of the two languages, even within a single utterance. Not all bilinguals code-switch, so the opportunity to examine contexts that do and do not support code-switching among bilingual speakers who are 
equally proficient reveals the linguistic and cognitive mechanisms at play in enabling this skilled mixing performance. The other uniquely bilingual aspect of language process consists of translation and interpretation. Only a small group of bilinguals become professional translators or interpreters. A question that arises is whether these individuals are a self-selected group who possess exceptional cognitive abilities to enable them to perform these tasks, or whether acquiring training in translation and interpretation itself imposes cognitive demands that sharpen these cognitive abilities. The research suggests the latter, but regardless of the answer to this question, translation and interpretation may be considered a form of extreme bilingualism that is virtually linguistic athleticism. Pushing duallanguage processing to its limits under these circumstances reveals the constraints and flexibility of the language system. In this article, we focus on the dynamics of cross-language interaction in these different contexts of language use.

\section{LANGUAGE LEARNING AND LANGUAGE PROCESSING UNDER CONDITIONS OF IMMERSION}

Early research on study abroad suggested that there were clear benefits for language learners when they were immersed in the L2 (e.g., Freed, 1995). More recently, the American Academy of Arts and Sciences published a report in 2017 on the state of language learning in the United States in which they noted that an intensive and integrated study abroad experience at the university level is sufficient to create high proficiency speakers of a foreign language, even for those who may have entered the university with little preparation and whose proficiency prior to the study abroad experience was quite low (for the statistical report from the Commission on Language Learning, see Commission on Language Learning, 2017). What happens when young adults are immersed in an L2 context? The assumption has generally been that language immersion is effective by virtue of increasing the frequency and intensity of exposure to the L2.

Although the frequency of L2 input and exposure is an important factor, there are many other factors that are likely to influence language learning under conditions of immersion, including social and cultural aspects of immersion and motivation to learn the language. The factor that has been the focus of much of the recent psycholinguistic research is the role of the L1. In some immersion contexts, it is difficult or impossible for learners to use their native language. But even in those contexts in which they can continue using the $\mathrm{L} 1$, it is reduced relative to the home environment. Here we consider the consequences of losing access to the native language when immersed in the L2.

\section{Evidence for Native Language Suppression During L2 Immersion}

Linck, Kroll, and Sunderman (2009) examined both production and comprehension performance in a group of native English-speaking students studying abroad in Spain. They compared the performance of the study abroad group with a matched 
group of English learners of Spanish studying in the United States in a classroom context. All learners were at an intermediate level of acquiring Spanish as the L2, though the classroom learners were selected to be at a somewhat more advanced level than the study abroad learners to avoid bias in favor of the immersed learners. In a semantic verbal fluency task, Linck et al. asked learners to produce a set of exemplars in English (the L1) and another set in Spanish (the L2). They were given 30 seconds to generate as many category members as possible in the designated language. All learners were dominant in English, as the L1 and produced more exemplars in English overall. There were two results of note. First, the immersed, study abroad group produced more Spanish than did the classroom group, suggesting a benefit that might be expected from the increased exposure to Spanish. But a second result was surprising - the immersed learners produced fewer words in English than the classroom learners. The finding suggests that the native language is less accessible when learners are immersed in the L2. The results of the comprehension measure, translation recognition, converged with the production results. In translation recognition, a word in the $\mathrm{L} 2$ is followed by a word in the L1, in this case Spanish and then English. The task is to decide if the L1 word is the correct translation of the L2 word (De Groot, 1992). For classroom learners, the typical pattern is that words that resemble the lexical form of the translation are easily mistaken for the correct translation (e.g., Sunderman \& Kroll, 2006; Talamas, Kroll, \& Dufour, 1999). Linck et al. found that both the immersed and classroom learners produced interference in translation recognition when the words were semantically related but that the immersed learners were no longer sensitive to the lexical distractors. Together, the results demonstrated reduced interference from the L1 and a suppression in the ability to speak words in the L1. Data on students following their return from study abroad also reveal a rebound effect, showing that the suppression of the native language is a typical consequence of immersion, not an indication of language attrition.

A subsequent study by Baus, Costa, and Carreiras (2013) using a picture-naming task replicated the reduction in lexical access in the L1 during immersion and further identified its source as low-frequency words that were not cognates across the two languages. That finding is similar to the claims about weaker links and frequency lag that identify the frequency of usage as determining the accessibility of words in each language (e.g., Gollan et al., 2011; for a review, see Kroll \& Gollan, 2014).

The research on language use during immersion is important in showing the natural dynamic between the two languages when the environmental support for L2 is increased. Although we need to be cautious about reliance on phenomenology, the experimental immersion data are quite consistent with the experience that students and travelers describe when living abroad. The reduction in access to the L1 can also be seen in studies of domestic immersion within the United States, where students spend a summer in a language school environment. Unlike the study abroad context, the domestic immersion environment enforces the absence of the native language, with strict rules about using the L2 only. Under these circumstances, there is enforced inhibition of the L1. Jacobs, Fricke, and Kroll 
(2016) showed that native English-speaking intermediate learners of Spanish in a domestic immersion program were more advanced than classroom learners in acquiring the phonetics of Spanish. Critically, the classroom learners were influenced by the cognate status of Spanish words, with more English-like production for cognates than noncognates. The immersed learners did not reveal this sensitivity, even following only a summer immersion program, which suggests that the context of learning had quickly and effectively reduced the activation of the L1 and influenced articulation in the L2.

The reduced access to the native language under conditions of language immersion is not restricted to the lexicon or phonology. Studies of sentence processing show that when highly proficient bilinguals are immersed in the L2, they also shift their parsing preferences in a way that reflects the influence of the L2 grammar on the L1 (e.g., Dussias \& Sagarra, 2007). It is beyond the scope of this article to fully elaborate on the implications of changes to the native language for an account of L2 learning and bilingualism (for a recent review, see Kroll, Dussias, Bice, \& Perrotti, 2015). Critically, the modulation of the L1 occurs quickly, both early in the time course of new learning (e.g., Bice \& Kroll, 2015) and in the course of an experimental manipulation in which bilinguals immersed in their native language environment are required to speak the L2 before speaking the L1 (e.g., Misra, Guo, Bobb, \& Kroll, 2012). The fact that these changes occur quickly, that they can be seen in both L2 learners and highly proficient bilinguals, that they vary as a function of the context in which the two languages are used, and that they can be documented in brain activity (see Green \& Kroll, in press) suggests that dynamic changes in the relative activation of the two languages is the normal state of affairs. It also suggests that generalizations about bilingual performance and the consequences of bilingualism need to carefully consider the context of language use.

A conclusion that can be drawn from the research on the modulation of the L1 is that L2 learners and bilinguals come to learn to regulate the native or dominant language to enable proficient use of the two languages. That regulation has been hypothesized to be related to cognitive control and also to the cognitive consequences of bilingualism (e.g., Green \& Abutalebi, 2013). Recent studies suggest that bilinguals come to coordinate the use of the two languages and that, as a result, they acquire the ability to coordinate inhibitory control functions more generally (e.g., Morales, Gómez-Ariza, \& Bajo, 2013). But language regulation and cognitive control are not identical; they draw on the same neural networks that enable control more generally but the way that language is used will tune the control networks in a manner that may reflect a more complex modulation of domain general processes (for an example of how prediction processes in L2 sentence processing for immersed bilinguals are modulated by the joint influence of language regulation and inhibitory control, see Zirnstein, Van Hell, \& Kroll, 2018).

We consider a final recent study that exploited the comparison across international locations to examine not only language performance but also its relation to domain general cognitive resources. Beatty-Martínez et al. (under review) 
compared the performance of three groups of highly proficient Spanish-English bilinguals in different locations. One group lived in Granada, Spain, where the two languages are used separately, with Spanish the majority language used for home and most social interactions, and English used for work and/or school. Bilinguals in Granada do not typically code-switch, using each language in primarily one context. The second group lived in Puerto Rico, where both languages are used in both home and work contexts, where code-switching is prevalent, and where virtually all individuals speak both languages. The third group lived in the United States, immersed in an L2 environment in which English was the majority language and surrounded by many speakers who bilingual or not, did not speak Spanish. Beatty-Martínez et al. compared performance on two lexical production tasks and on a measure of proactive/reactive inhibitory control. The important finding for present purposes concerns picture-naming performance. Notably, all three groups were highly proficient and able to name pictures in both Spanish and English, with accuracy above $90 \%$. For the immersed bilinguals in the United States, the accuracy of picture naming was modulated by inhibitory control ability. For the other two bilingual groups, there was no relation between picture naming and inhibitory control ability. The interpretation is that only the immersed bilinguals in the United States were faced with making a decision about speaking Spanish or code-switching. Not everyone spoke Spanish, and they were required to actively monitor the environment before planning speech. The bilinguals in Granada could use the relative separation of the English and Spanish environments to enable proficient speech planning. Likewise, the bilinguals in Puerto Rico, although quite distinct from those in Granada, were also not faced with decision making because all potential interlocutors provided an opportunity to speak either language or to mix them. In most investigations of bilingualism, these three highly proficient groups of Spanish-English speakers would be considered the same. The differences across these contexts of language use makes clear that they are not. The differences that were observed in this study also make clear that before concluding that a particular study fails to replicate some finding in the previous literature, one needs to take into account the nuances of the language environment. ${ }^{2}$

IMMERSION EFFECTS DURING THE PROCESSING OF CODE-SWITCHED LANGUAGE

Since the first psycholinguistic experiments investigating bilingual language switching were conducted by Kolers (1966) and by Macnamara and colleagues in subsequent years (Macnamara, 1967; Macnamara \& Kushnir, 1971; Macnamara, Krauthammer, \& Bolgar, 1968), research on bilingual code-switching has received increased attention, especially in recent years (Balukas \& Koops, 2015; Deuchar, Muysken, \& Wang, 2007; Deuchar \& Stammers, 2012; Fricke \& Kootstra, 2016; Green \& Abutalebi, 2013; Gullifer, Kroll, \& Dussias, 2013; Kootstra \& Muysken, 2017; Kootstra, Van Hell, \& Dijkstra, 2010; Muysken, 2000; Myslín \& Levy, 2015; Torres Cacoullos \& Travis, 2018). Code-switching, usually defined as a linguistic 
behavior in which bilingual speakers alternate between their languages-often several times within a single sentence-is common in many bilingual communities. Bilinguals code-switch when speaking to other bilinguals, but also when they write to one another in informal contexts. The following email illustrates this (Spanish in bold, translation in square brackets; sender's name has been replaced with $\mathrm{XXXX}$ to ensure anonymity):

Thursday, February 1, 2018, at 11:00:00 [XXXX]wrote:

Sí, hablemos este fin de semana. Ya no me acuerdo, ¿estás de vuelta en State College? ¿a qué hora quieres hablar? Por la mañana es mejor para mí-como a las 8am (sábado o domingo), which I figure is probably better for you anyways. ¿qué te parece? También te quería comentar that I have good news and bad news: the good news is that....

[Yes, let's talk this weekend. I can't remember now, are you back in State College? what time do you want to talk? Mornings are better for me-like at 8am (Saturday or Sunday), which I figure is probably better for you anyways. what do you think? I also wanted to tell you that I have good news and bad news: the good news is that....]

The fact that bilinguals code-switch in written discourse, where language planning demands are more easily mitigated relative to spoken language production, does not support the popular view that code-switching is triggered by a break in the fluency of speech (e.g., lexical gaps); rather it suggests that during language planning, bilinguals code-switch to better convey meaning or pragmatic intention (Myers-Scotton, 1993), and that code-switching, like other forms of speech, reflects "production behavior [that] is shaped by learned implicit strategies that maximize fluency" (for a discussion in monolingual contexts, see MacDonald, 2013, p. 3 ).

The bulk of research on code-switching has come from sociolinguistic and formal perspectives, and it has investigated the social contexts and structural constraints that guide the production of code-switched speech. More recently, psycholinguists and cognitive psychologists have employed time-sensitive measures of language processing - such as eye-tracking and electrophysiological methodsand brain imaging techniques to study the comprehension of code-switches on the fly (e.g., Beatty-Martínez \& Dussias, 2017; Fricke, Kroll, \& Dussias, 2016; Guzzardo Tamargo, Valdés Kroff, \& Dussias, 2016; Johns, Valdés Kroff, \& Dussias, in press; Litcofsky \& Van Hell, 2017; Moreno, Federmeier, \& Kutas, 2002; Valdés Kroff, Dussias, Gerfen, Perrotti, \& Bajo, 2017; Wicha, Moreno, \& Kutas, 2004). One goal of this work is to uncover the underlying cognitive and linguistic mechanisms that regulate code-switching. Although originally considered a sign of linguistic incompetence and mental laziness (for a discussion, see Heredia \& Altarriba, 2001), linguists have long noted that code-switching is not haphazard and requires a great deal of proficiency and cognitive control in the two languages (e.g., Kroll et al., 2015; Lipski, 1978; Pfaff, 1979; Poplack, 1980, 2015; Timm, 1975; Torres Cacoullos \& Travis, 2018). 
As we might expect, just as monolingual speakers sometimes exhibit processing costs during online language comprehension (e.g., Frazier, 1987; Gennari \& MacDonald, 2009; Reali \& Christiansen, 2007; Traxler, Morris, \& Seely, 2002), bilingual speakers have shown costs when processing code-switched sentences (for a review, see Van Hell, Litcofsky, \& Ting, 2015). Recent studies have also shown that these costs are reduced when bilinguals are immersed in code-switching environments (e.g., Beatty-Martínez \& Dussias, 2017; Fricke et al., 2016; Guzzardo Tamargo et al., 2016). For example, Beatty-Martínez and Dussias (2017) examined whether bilinguals' electrophysiological responses to a well-documented grammatical gender asymmetry in Spanish-English mixed-noun phrases (Otheguy \& Lapidus, 2003; Valdés Kroff, 2016) differed as a function of code-switching immersion experience.

Briefly, Spanish noun phrases are governed by the requirement that determiners and nouns must match in grammatical gender (Eddington, 2002). A determiner marked with feminine gender must be followed by a noun carrying feminine gender assignment, and a determiner marked with masculine gender must be followed by a similarly marked masculine noun. The asymmetry observed in Spanish-English code-switching corpora is related to a partial "violation" of this requirement. Code-switches headed by the Spanish feminine article $l a$ (English "the") are typically followed by an English noun whose Spanish translation equivalent is also feminine (e.g., la blender/licuadora ${ }_{\text {FEMm }}$ but not $* l a$ shoe/zapato ${ }_{\text {MAS }}$ ). This is what we might expect if participants were employing a "gender congruency" strategy when producing mixed-noun phrases. The violation comes when the determiner is marked with masculine gender. In these cases, the Spanish masculine determiner $e l$ (also "the") surfaces with English nouns whose Spanish translation equivalents are masculine ( $e l$ shoe/zapato ${ }_{\text {MAS }}$ ) or feminine ( $e l$ blender/licuadora ${ }_{\text {FEM }}$ ). In Beatty-Martínez and Dussias (2017), participants who were Spanish-English bilinguals immersed or not in a code-switching environment, read short vignettes containing gender-congruent determiner-noun switches ( $e l$ shoe/zapato ${ }_{\mathrm{MAS}} ; l a$ blender/licuadora $\left.{ }_{\mathrm{FEM}}\right)$ and gender incongruent ones $(* l a$ shoe/zapato ${ }_{\mathrm{MAS}} ; \mathrm{el}$ blender/licuadora $\left.{ }_{\mathrm{FEM}}\right)$. Code-switchers demonstrated labored processing only with gender incongruent targets such as "la shoe." Critically, non-code-switchers processed the two types of incongruent code-switches with similar difficulty. This suggests that the bilinguals immersed in a code-switching environment were highly sensitive to the variation in their language experience and demonstrates that switching costs are modulated by the experience with the input in the environment (for results with code-switches involving the verb phrase, see Guzzardo Tamargo et al., 2016).

Similar findings are reported in a recent study by Adamou and Shen (in press), who used a picture-sentence matching task to test whether switching costs were modulated by frequent exposure to specific code-switched constructions. Stimuli included ecologically valid code-switches constructed to mirror the types of switches found in natural conversations in the participants' speech community. Processing of these switches was compared to that of switches with lesser degrees of ecological validity. The central finding was that switched trials that were based 
on the participants' code-switching experience (in the form of the more ecological valid ones) were just as fast to process as unilingual trials.

A more striking effect of immersion in the context of code-switching was reported in Valdés Kroff et al. (2017). They asked whether L1 Spanish-L2 English bilinguals used grammatical gender information encoded in Spanish articles to anticipate the gender of upcoming nouns, while processing speech entirely in Spanish - the bilinguals' dominant language. Past work has demonstrated that monolingual speakers of Spanish exploit gender information present in determiners such as $e l$ and $l a$ to anticipate the gender of an ensuing noun (e.g., Lew-Williams $\&$ Fernald, 2007). Given the gender asymmetry effect in mixed-noun phrases, one question is whether being immersed in a code-switching environment will impact the bilinguals' ability to use grammatical gender anticipatorily. To investigate this, Valdés Kroff et al. recorded the eye movements of Spanish-English bilinguals who lived in a community where code-switching was part of the linguistic repertoire, while participants listened to code-switched sentences (e.g., Hay un niño que está mirando el candy/There is a boy looking at the candy MASC $_{\text {) }}$ in the presence of a two-pictured object scene. In the critical condition, the lexical gender of the two objects was different - a picture of a blender (licuadora ${ }_{\mathrm{FEM}}$ ) and a picture of a shoe (zapato MAS). The interesting result was that code-switchers showed an anticipatory effect, but only in trials with a feminine determiner. When the determiner was masculine, participants did not launch anticipatory looks, but rather waited to hear the target noun. This suggests that the bilinguals did not use masculine articles as cues for anticipatory processing - a result congenial with an immersion-based view in which the extensive use of $e l$ as a "default" article in code-switching led the bilinguals to a "wait-and-see" strategy.

One important question concerns the mechanisms that may be responsible for the key role that immersion experience plays in the processing of code-switches. Psycholinguistic studies examining monolingual linguistic behavior have shown that comprehension and production involve many of the same representations and processes (Treiman, Clifton, Meyer, \& Wurm 2003). In comprehension, listeners map the signal onto lexical entries whose semantic and syntactic information becomes available for constructing the syntactic structure and meaning of utterances. Similarly, in production, speakers select lexical items, each carrying syntactic and morphological features affecting the selection of additional words (Treiman et al., 2003). Given this, studies have investigated how comprehension and linguistic experience interact. One model that argues for the existence of a close correspondence between comprehension and production patterns in the environment is the production-distribution-comprehension (PDC) framework (MacDonald, 2013; MacDonald \& Thornton, 2009). The premise of the model is that effects observed during comprehension derive from particular distributional patterns in production, which in turn create distributional regularities that shape comprehenders' expectations. For instance, it has been well documented in the psycholinguistic literature that when English speakers read the sentence "Mary said that John left yesterday," they typically interpret it to mean that the leaving event took place yesterday, even though the adverb could plausibly refer to the saying event. According to the 
PDC, this is not because of hardwired constraints on the comprehension system (e.g., expressions like "yesterday" initially modify the verb that is nearest). Instead, the preferences observed during comprehension are learned from patterns in the input that arise from constraints on production. The PDC framework grants a major role to frequency: Frequent constructions are more readily activated by appropriate information sources than less common constructions. For example, studies show that comprehension difficulty is influenced by the match between syntactic structure and the frequency with which verbs appear in that structure. Thus, transitive verbs (e.g., believe) most often used by speakers with sentential complements cause less comprehension difficulty when followed by a sentential complement than by a noun phrase complement (Garnsey, Pearlmutter, Myers, \& Lotocky 1997; Spivey-Knowlton \& Sedivy 1995; Trueswell \& Kim 1998). Based on this evidence, we would expect exposure to code-switched constructions to modulate comprehension, and this is precisely what the evidence discussed here shows.

Together, the results in this section suggest that the comprehension system becomes optimally attuned to variation in the input and provide evidence that bilinguals are highly sensitive to the constraints of their linguistic experience. Particularly regarding code-switching, the findings demonstrate how the processing of code-switched language largely depends on the type of code-switches available in the participants' discourse environment.

\section{TRANSLATION AND INTERPRETATION}

Translation and language interpretation is an extremely demanding instance of the multilingual context. ${ }^{3}$ The role of expertise in translation has been explored in relation to the linguistic and cognitive processes involved in translation and interpreting tasks (Christoffels \& De Groot, 2005; Christoffels, De Groot, \& Kroll, 2006; Ibáñez, Macizo, \& Bajo, 2010; Macizo \& Bajo, 2006). Translators are a special type of multilingual individual not only because they usually master three or more languages at a very proficient level but also because language use of each of these languages differ from that of other type of bilinguals. When translators perform translation tasks, they have to comprehend and reformulate a given message expressed in one language into another language. Despite differences among the existing varieties of translation tasks, the main characteristic of the translation performance is that while translators have to understand and reformulate a message from one language to another, they must also maintain the two relevant languages actively and switch continually between them, while avoiding interference. The evidence suggests that translators activate the two relevant languages during online comprehension for later translation. Even when they are consecutively comprehending in one language and translating into another (Christoffels, Ganushchak, \& Koester, 2013; Macizo \& Bajo, 2006, Ruiz, Paredes, Macizo, \& Bajo, 2008), they access lexical and syntactic translation equivalents from the start of the translation process when they are still comprehending the presented sentences. For example, 
Macizo and Bajo (2006, Experiment 2) asked professional translators to perform interpretation of the utterances presented visually (they had to read sentences in Spanish and translate them into English). The cognate status of keywords was manipulated to assess if the participants had access lexical/semantic forms to the target language (TL) before they completed comprehension of the source language (SL). Reading times for cognate words in Spanish were faster than reading times for control words. Moreover, this cognate facilitation effect solely occurred when professionals read for translation; no effect was found when they were asked to perform the reading for repetition task, suggesting that lexical processing varies as a function of the linguistic task. Similarly, Ruiz et al. (2008, Experiment 1) provided further evidence for this flexible use of language by manipulating the frequency of the translation equivalents or the SL/TL congruency of the preferred word orders for sentences that had to be translated. This pattern suggests that translation involves simultaneous processing at many levels, given that not only comprehension and production are performed simultaneously in two different parallel languages, but also TL language activation and search for translation equivalents occur while comprehension is taking place. Despite simultaneity, translators need to be able to keep their two languages separated and monitor their input and output mechanisms in a way that allows them to input the SL and to output the TL without interference (Grosjean, 1997).

Results obtained by Ibáñez et al. (2010) suggest that bilinguals may differ in the way they negotiate their two (or more) languages. In their study, Ibáñez et al. asked professional translators and untrained bilinguals to read and understand sentences presented word by word, and then repeat them in the language of presentation (Spanish: L1 or English: L2) once they had finished reading them. To explore the nonselective activation of both languages, they introduced cognate words (e.g., zebra/cebra, in English/Spanish) in the sentences and compared their reading times to control noncognate words. The presence of cognate effects (faster reading to cognates relative to control words) was taken as an index of between-language activation (Dijkstra, Grainger, \& Van Heuven, 1999; Kroll \& Stewart, 1994; Macizo \& Bajo, 2006). In addition, to explore the nature of the lexical selection mechanism, Ibáñez et al. adapted the language-switching paradigm (e.g., Costa \& Santesteban, 2004; Kroll \& Stewart, 1994; Meuter \& Allport, 1999; Thomas \& Allport, 2000) to a sentence-reading task. Thus, the sentences were presented in Spanish (L1) or English (L2) in an unpredictable manner. The presence of asymmetrical switching costs (switching into the dominant L1 produced larger switching costs than switching into the less dominant L2) was taken as an index of inhibitory control. This procedure also had the advantage of mimicking comprehension in bilateral translation, where translators listen and comprehend sentences uttered from two or more speakers of different languages. The results showed that translators were different from the control bilinguals in that the translated continued to be faster to process cognate words as compared to control words. Furthermore, they did not show asymmetrical language-switching costs (index of inhibition), whereas the bilingual group showed slower responses when switching for their L2 to their L1 (asymmetrical switching cost). These results suggest that translators differ from 
bilinguals in the way they control their languages during comprehension so that they kept them both active (cognate effects) and showed no evidence of inhibition. The results of the present study suggest that translators do not use inhibitory processes to control for the concurrent activation of their two languages. The fact that the translator presented cognate effects during reading suggests that inhibition was not used to control their languages. To further provide support for this observation, Martín (2010) used the negative priming with interlingual homographs procedure with professional translators. In this task, pairs of English words were presented to bilinguals immersed in their L1 or L2, and they had to decide whether or not they were semantically related. The word pairs were presented in English (the participants' L2). The task was carried out in blocks of two trials. In the first trial, pairs of unrelated English words were presented, so the participants' correct response was "no." In the critical condition, an interlingual homograph (e.g., pie, meaning "foot" in Spanish) was presented along with another word that was unrelated to the English meaning of the homograph but related to the Spanish meaning (e.g., pie-toe). When a pair like pie-toe was presented, participants had to respond "no," because both words are unrelated in English. This condition was compared to a control condition in which a matched nonhomograph word along with an unrelated English word was presented (e.g., log-toe). This first trial aimed to capture L1 activation during L2 processing, given that activation of the irrelevant homograph meaning would make participants to take longer to respond in the homograph-unrelated condition than in the control-unrelated condition. The second trial aimed to capture the inhibition needed to overcome interference. Thus, in this trial, pairs of English-related words were presented, so that the participants' correct response was "yes." In the critical condition, the English translation of the non-target homograph meaning (e.g., foot) was presented along with a related word (e.g., hand). This condition was compared to a control-related condition in which a matched related word was presented along with an English word (e.g., finger-hand). Longer response times in the translation-related condition as compared to the control-related condition when preceded by the homograph-unrelated condition (e.g., foot-hand preceded by pie-toe) indicated that the L1 irrelevant homograph meaning was inhibited in the first trial. The Spanish-English bilinguals were slower in responding to homograph trials than to control trials, indicating that they experienced interference because of the activation of the non-target L1 homograph meaning. Furthermore, after responding to homographs, these bilinguals slowed their responses when the irrelevant homograph meaning became relevant in the second trial (see also Macizo, Bajo, \& Martín, 2010). Consistent with data presented by Ibáñez et al. (2010), the translators showed evidence of language co-activation, because they were slower when interlingual homographs were presented during the first trial; however, and differently from bilingual controls, they did not show slower responses when the translation of the irrelevant meaning was presented in the second trial after presentation of the homograph in the first trial, suggesting that translators do not rely on inhibition, but rather use other mechanisms that allow them to maintain two active languages (for a similar pattern with an $n-2$ repetition switching task, see Babcock \& Vallesi, 2015). 
The question is, then, how do professional translators control their languages? Because interpreters must comprehend the SL while producing and monitoring their output in the TL, they seem not to rely mainly on inhibition as a way of managing their two languages, and therefore another cognitive mechanism might also be involved. Results looking at the cognitive abilities of professional translators seem to suggest that language control in translators, similar to other bilinguals, requires the right balance between proactive and reactive control, but with a clear bias toward proactive processes and mechanisms such as monitoring, updating, dual tasking, or working memory. The idea is that proactive control processes (Braver, 2012; Morales et al., 2013, Morales, Yudes, Gómez-Ariza, \& Bajo, 2015) may help translators to reduce interference before it occurs. Proactive control means that goal representations are triggered in preparation for the task and maintained during periods in which they are required. From this view, translators may be continuously monitoring intra- and extra-language cues to select the appropriate language for comprehension and production (for discussion of this view for very balanced bilinguals, see Costa, La Heij, \& Navarrete, 2006; Costa, Santesteban, \& Ivanova, 2006).

Thus recent studies comparing professional translators to other bilinguals and monolingual participants in tasks, such as Stroop or Simon, that index inhibition showed that the interpreters were not better than the students and controls in avoiding interference (Köpke \& Nespoulous, 2006, Yudes, Macizo, \& Bajo, 2012). However, they showed better performance in working memory tasks (Christoffels et al., 2006; McNamara \& Conway, 2015; Morales, Padilla, Gómez-Ariza, Bajo, 2015; Padilla, Bajo, \& Macizo, 2005; Signorelli, Haarmann \& Obler, 2011; Stavrakaki, Megari, Kosmidis, Apostolidou, \& Takou, 2012), fewer monitoring errors, and more flexible behavior in the Wisconsin Card Sorting Task (Yudes et al., 2012). Larger working memory and monitoring processes support proactive language control that allows faster language activation and less costly language switching during comprehension and production. Enhanced ability to actively maintaining two sets and efficiently switching between them has been further supported by two recent studies showing smaller mixing costs (mixed-task blocks versus single-task blocks) in task-switching procedures (Babcock \& Vallesi, 2015, 2017). Similarly, the interpreters' skill to perform and coordinate simultaneous tasks has been assessed by using the PRP (psychological refractory period) in single- and dual-task situations (Strobach, Becker, Schubert, \& Kühn, 2015). In the dual-task condition, participants are asked to perform two different choice reaction time (RT) tasks as fast as possible. The two tasks are separated by a variable interval, and participants are instructed to give priority to the performance of Task 1 . This specific PRP situation typically shows dual-task performance costs by RT in Task 2 (RT2-dualRT) that increase with decreasing stimulus onset asynchrony (SOA; PRP effect). RTs in Task 1 (RT1) usually remains constant. Results comparing participants with and without interpreting experiences showed that RT2 and RT1 in dual tasks were faster in experienced participants, indicating that superior task coordination in the present PRP situation might be associated with the performance and coordination of multiple, simultaneous tasks during interpreting. 
In sum, research on translation and language interpretation suggests that language use in this extreme bilingual situation differs from other bilingual contexts because the two languages need to be coordinated and used in a flexible manner. A recent study by Togato, Paredes, Macizo, and Bajo (2017) comparing monolingual reading and reading for translation of syntactically ambiguous sentences (e.g., "Someone shot the servant of the actress who was on the balcony") illustrates the highly flexible and adaptive use of language by interpreters. Although previous research has shown attachment preferences for the first (Spanish speakers) or second (English speakers) antecedent ("servant" and "actress") for the subordinate clause (who was on the balcony) depending on the language of the speaker (Carreiras \& Clifton, 1999; Gilboy, Sopena, Clifton, \& Frazier, 1995), professional translators flexibly used the attachment strategy preferred in the output language when they performed the interpreting task (read the sentence for later translation). Hence the comprehension and production systems of the translators seem to adapt to the constraints imposed by the linguistic tasks in a goal-oriented manner. Interestingly, their cognitive skills seem to be particularly attuned to the needs of the bilingual task.

\section{CONCLUSIONS}

The research we have reviewed in this article points to an important role for comparative studies that take a global perspective to contrast $\mathrm{L} 2$ learning and bilingualism in contexts that differ in the support and arrangements they provide for the two languages. The theme that emerges in our review is that learning and using two languages creates a dynamic within the language system that enables individuals to juggle the two languages with a high degree of proficiency under radically different conditions. But the two languages and their reliance on cognitive resources change as a function of the context, even for the same individual across the life span. There is a great deal that we still do not know about which of these changes are reversible and which create enduring consequences for bilingual minds and brains. We are also just beginning to see how the cognitive and neural consequences of bilingualism may depend on the contexts in which the two languages are learned and used. Many have assumed that we can simply ask whether bilingualism produces differences in cognitive functions. This brief review suggests that the question is far more complex and that an adequate answer to this question will require a consideration of how bilingualism differs across individuals and the environments in which they use the two languages.

One clear implication in the findings we have reviewed is that there is sometimes a cost associated with immersion experience and with the associated suppression of the native or dominant language. That cost has often been misinterpreted as a disadvantage, but research on learning and memory suggests that it may in fact be a desirable difficulty, something that increases the initial difficulty of learning but gives rise to errors from which individuals are likely to learn, and to elaboration that will benefit the stability of later memory (e.g., Bjork, Dunlosky, \& Kornell, 
2013; Bjork \& Kroll, 2015; Bogulski, Bice, \& Kroll, in press). Future studies that investigate both the short-term and long-term consequences of the language environment will be crucial to determine the scope of these effects and to determine whether language processing costs ultimately translate into benefits under the right conditions.

A further implication of the research on language immersion is that it provides a preliminary framework for better understanding the consequences of heritage language experience. In the United States, this is an issue of particular importance for educating young learners who have grown up with a language in the home other than English and then, when entering school, are faced with a requirement to switch into English. The evidence in the recent report issued by the American Academy of Arts and Sciences (Commission on Language Learning, 2017) suggests that duallanguage immersion that maintains the home language has benefits that extend beyond the home language itself to developing language and academic skills in English. But there is a gap between the research on adult learners immersed here or abroad and child learners. Recommendations from those investigating bilingual education include the idea of more freely mixing the two languages during instruction, something that has been called translanguaging (e.g., García \& Wei, 2014). Although translanguaging and code-switching are not the same, it will be important in this next phase of research that we begin to consider how the evidence on language mixing in different contexts might relate to programs of dual-language instruction. Likewise, it will be of interest to relate the findings on translation and interpretation we have reviewed, which reveal flexibility in language processing and cognitive control in adults, to the experience of child language brokers, who regularly translate for their parents and caregivers (e.g., López \& Vaid, 2018).

To conclude, we have attempted to show that international collaboration and comparative studies that exploit the features of different contexts of language learning and language use hold great promise to reveal the boundary conditions that define the very meaning of bilingualism. The result may be a research program that is more complex, but it is also one that is richer and more likely to bridge laboratory research to its translation in the communities of language users across the globe.

\section{Acknowledgments}

The writing of this article was supported in part by National Science Foundation grants BCS-1535124 and OISE-1545900 to Paola E. Dussias and Judith F. Kroll, National Institutes of Health grants HD071758 to Paola E. Dussias and HD082796 to Judith F. Kroll, and MINECO-PCIN-2015-132 and MINECO- PSI2015-65502C2-1-P to María Teresa Bajo.

\section{NOTES}

1. The co-authors are partners in an international research network on bilingualism and language learning supported by a U.S. National Science Foundation PIRE (Partnerships for International Research and Education) grant. 
2. The analysis we present might suggest that bilinguals would be exquisitely sensitive to cues in the environment that signal the use of one of the two languages. Curiously, there is very little evidence for reliance on external cues to language status. Zhang, Morris, Cheng, and Yap (2013) reported production data on Chinese-English bilinguals immersed in the United States in an English-speaking environment. They showed that Chinese speakers were less fluent in English when speaking to other Chinese speakers or in the context of cues to Chinese culture. Likewise, Li, Yang, Scherf, and Li (2013) showed that bilinguals were sensitive to congruence between speaker's faces and language.

3. Although simultaneous interpretation may be understood as a uniquely demanding task because of the real-time constraints, we consider both translation and interpretation tasks in this section because they each impose demands on bilingual speakers that differ from the ordinary context of bilingualism and, as such, reveal important features of how cognitive resources are used to support language processes.

\section{REFERENCES}

Adamou, E., \& Shen, X. R. (in press). There are no language switching costs when codeswitching is frequent. International Journal of Bilingualism. doi: https://doi.org/10.1177/1367006917709094

Babcock, L., \& Vallesi, A. (2015) Language control is not a one-size-fits-all languages process: Evidence from simultaneous interpretation students and the $n-2$ repetition cost. Frontiers in Psychology, 6. doi: 10.3389/fpsyg.2015.01622

Babcock, L., \& Vallesi, A. (2017). Are simultaneous interpreters expert bilinguals, unique bilinguals, or both? Bilingualism: Language and Cognition, 20, 403-417.

Balukas, C., \& Koops, C. (2015). Spanish-English bilingual voice onset time in spontaneous codeswitching. International Journal of Bilingualism, 19, 423-443.

Baus, C., Costa, A., \& Carreiras, M. (2013). On the effects of second language immersion on first language production. Acta Psychologica, 142, 402-409.

Beatty-Martínez, A. L., \& Dussias, P. E. (2017). Bilingual experience shapes language processing: Evidence from codeswitching. Journal of Memory and Language, 95, 173-189.

Beatty-Martínez, A. L., Navarro-Torres, C. A., Dussias, P. E., Bajo, M. T., Guzzardo Tamargo, R. E., \&. Kroll, J. F. (under review). Beyond simple replication: Interactional context of language use determines the consequences of bilingualism.

Bialystok, E., \& Kroll, J. F. (in press). The neurobiology of language: Looking beyond monolinguals. Special issue of Biolinguistics celebrating the 50-year anniversary of Eric Lenneberg's Biological foundations of language.

Bice, K., \& Kroll, J. F. (2015). Native language change during early stages of second language learning. NeuroReport, 26, 966-971.

Bjork, R. A., Dunlosky, J., \& Kornell, N. (2013). Self-regulated learning: Beliefs, techniques, and illusions. Annual Review of Psychology, 64, 417-444.

Bjork, R. A., \& Kroll, J. F. (2015). Desirable difficulties in vocabulary learning. American Journal of Psychology, 128, 241-252.

Bogulski, C. A., Bice, K., \& Kroll, J. F. (in press). Bilingualism as a desirable difficulty: Advantages in word learning depend on regulation of the dominant language. Bilingualism: Language and Cognition.

Braver, T. S. (2012). The variable nature of cognitive control: A dual mechanisms framework. Trends in Cognitive Sciences, 16, 106-113.

Caffarra, S., Molinaro, N., Davidson, D., \& Carreiras, M. (2015). Second language syntactic processing revealed through event-related potentials: An empirical review. Neuroscience \& Biobehavioral Reviews, 51, 31-47.

Carreiras, M., \& Clifton, C. (1999). Another word on parsing relative clauses: Eyetracking evidence from Spanish and English. Memory \& Cognition, 27, 826-833.

Christoffels, I. K., \& De Groot, A. M. B. (2005). Simultaneous interpreting: A cognitive perspective. In J. F. Kroll \& A. M. B. De Groot (Eds.), Handbook of bilingualism: Psycholinguistic approaches (pp. 326-348). New York, NY: Oxford University Press.

Christoffels, I. K., De Groot, A. M. B., \& Kroll, J. F. (2006). Memory and language skills in simultaneous interpreters: The role of expertise and language proficiency. Journal of Memory and Language, 54, 324-345.

Christoffels, I. K., Ganushchak, L., \& Koester, D. (2013). Language conflict in translation: An ERP study of translation production. Journal of Cognitive Psychology, 25(5), 646-664. 
Clahsen, H., \& Felser, C. (2006). Grammatical processing in language learning. Applied Psycholinguistics, 27, 3-42.

Commission on Language Learning. (2017). America's languages: Investing in language education for the 21st century. Cambridge, MA: American Academy of Arts and Sciences. Retrieved from https://www.amacad.org/content/Research/researchproject.aspx?d=21896

Costa, A., La Heij, W., \& Navarrete, E. (2006). The dynamics of bilingual lexical access. Bilingualism: Language and Cognition, 9, 137-151.

Costa, A., \& Santesteban, M. (2004). Lexical access in bilingual speech production: Evidence from language switching in highly proficient bilinguals and L2 learners. Journal of Memory and Language, 50, 491-511.

Costa, A., Santesteban, M., \& Ivanova, I. (2006). How do highly proficient bilinguals control their lexicalization process? Inhibitory and language-specific selection mechanisms are both functional. Journal of Experimental Psychology: Learning, Memory, and Cognition, 32, 1057-1074.

De Groot, A. M. B. (1992). Determinants of word translation. Journal of Experimental Psychology: Learning, Memory, and Cognition, 18, 1001-1018.

Deuchar, M., Muysken, P., \& Wang, S. (2007). Structured variation in codeswitching: Towards an empirically based typology of bilingual speech patterns. International Journal of Bilingual Education and Bilingualism, 10, 298-340.

Deuchar, M., \& Stammers, J. R. (2012). What is the "nonce borrowing hypothesis" anyway? Bilingualism: Language and Cognition, 15, 649-650.

Dijkstra, T., Grainger, J., \& Van Heuven, W. (1999). Recognition of cognates and interlingual homographs: The neglected role of phonology. Journal of Memory and Language, 518, 496-518.

Dussias, P. E., \& Sagarra, N. (2007). The effect of exposure on syntactic parsing in Spanish-English bilinguals. Bilingualism: Language and Cognition, 10, 101-116.

Eddington, D. (2002). Spanish gender assignment in an analogical framework. Journal of Quantitative Linguistics, 9, 49-75.

Frazier, L. (1987). Sentence processing: A tutorial review. In M. Coltheart (Ed.), Attention and performance (pp. 559-586). Hillsdale, NJ: Erlbaum.

Freed, B. F. (Ed.). (1995). Second language acquisition in a study abroad context. Philadelphia, PA: John Benjamins.

Fricke, M., \& Kootstra, G. J. (2016). Primed codeswitching in spontaneous bilingual dialogue. Journal of Memory and Language, 91, 181-201.

Fricke, M., Kroll, J. F., \& Dussias, P. E. (2016). Phonetic variation in bilingual speech: A lens for studying the production-comprehension link. Journal of Memory and Language, 89, 110-137.

Fricke, M., Zirnstein, M., Navarro-Torres, C., \& Kroll, J. F. (in press). Bilingualism reveals fundamental variation in language processing. Bilingualism: Language and Cognition. doi: $10.1017 / \mathrm{S} 1366728918000482$

García, O., \& Wei, L. (2014). Translanguaging and education. In O. García \& L. Wei (Eds.), Translanguaging: Language, bilingualism and education. (pp. 63-77). London, UK: Palgrave Macmillan.

Garnsey, S. M., Pearlmutter, N. J., Myers, E., \& Lotocky, M. (1997). The contributions of verb bias and plausibility to the comprehension of temporarily ambiguous sentences. Journal of Memory and Language, 37, 58-93.

Gennari, S. P., \& MacDonald, M. C. (2009). Linking comprehension to production: The case of relative clause. Cognition, 111, 1-23.

Gilboy, E., Sopena, J. M., Clifton, C. Jr., \& Frazier, L. (1995). Argument structure and association preferences in Spanish and English complex NPs. Cognition, 54, 131-67.

Gollan, T. H., Slattery, T. J., Goldenberg, D., Van Assche, E., Duyck, W., \& Rayner, K. (2011). Frequency drives lexical access in reading but not in speaking: The frequency-lag hypothesis. Journal of Experimental Psychology: General, 140, 186-209.

Green, D, W., \& Abutalebi, J. (2013). Language control in bilinguals: The adaptive control hypothesis. Journal of Cognitive Psychology, 25, 515-530.

Green, D. W., \& Kroll, J. F. (in press). The neurolinguistics of bilingualism. To appear in G. de Zubicaray, \& N. Schiller (Eds.), Oxford handbook of neurolinguistics. New York, NY: Oxford University Press.

Grosjean, F. (1989). Neurolinguists, beware! The bilingual is not two monolinguals in one person. Brain and Language, 36, 3-15.

Grosjean, F. 1997. The bilingual individual. Interpreting, 2, 163-187.

Gullifer, J. W., Kroll, J. F., \& Dussias, P. E. (2013). When language switching has no apparent cost: Lexical access in sentence context. Frontiers in Psychology, 4, 1-13. 
Guzzardo Tamargo, R., E., Valdés Kroff, J. R., \& Dussias, P. E. (2016). Examining the relationship between comprehension and production processes in code-switched language. Journal of Memory and Language, 89, 138-161.

Heredia, R. R., \& Altarriba, J. (2001). Bilingual language mixing: Why do bilinguals code-switch? Current Directions in Psychological Science, 10, 164-168.

Ibáñez, A. J., Macizo, P., \& Bajo, M. T. (2010). Language access and language selection in professional translators. Acta Psychologica, 135, 257-266.

Jacobs, A., Fricke, M., \& Kroll, J. F. (2016). Cross-language activation begins during speech planning but extends into second language speech. Language Learning, 66, 324-353.

Johns, M., A., Valdés Kroff, J. R., \& Dussias, P. E. (in press). Mixing things up: How blocking and mixing affect the processing of codemixed sentences. International Journal of Bilingualism. doi: $10.1177 / 1367006917752570$

Johnson, J. S., \& Newport, E. L. (1989). Critical period effects in second language learning: The influence of maturational state on the acquisition of English as a second language. Cognitive Psychology, 21, 60-99.

Kolers, P. A. (1966). Reading and talking bilingually. American Journal of Psychology, 79, 357-376.

Kootstra, G. J., \& Muysken, P. (2017). Cross-linguistic priming in bilinguals: Multidisciplinary perspectives on language processing, acquisition, and change. Bilingualism: Language and Cognition, 20, 215-218.

Kootstra, G. J., Van Hell, J. G., \& Dijkstra, T. (2010). Syntactic alignment and shared word order in code-switched sentence production: Evidence from bilingual monologue and dialogue. Journal of Memory and Language, 63, 210-231.

Köpke, B., \& Nespoulous, J.-L. (2006). Working memory performance in expert and novice interpreters. Interpreting, 8, 1-23.

Kroll, J. F., Dussias, P. E., Bice, K., \& Perrotti, L. (2015). Bilingualism, mind, and brain. Annual Review of Linguistics, 1, 377-394.

Kroll, J. F., \& Gollan, T. H. (2014). Speech planning in two languages: What bilinguals tell us about language production. In V. Ferreira, M. Goldrick, \& M. Miozzo (Eds.), The Oxford handbook of language production (pp. 165-181). Oxford, UK: Oxford University Press.

Kroll, J. F., \& Stewart, E. (1994). Category interference in translation and picture naming: Evidence for asymmetric connections between bilingual memory representations. Journal of Memory and Language, 33, 149-174.

Lenneberg, E. (1967). Biological foundations of language. New York, NY: Wiley.

Li, Y., Yang, J., Scherf, K. S., \& Li, P. (2013). Two faces, two languages: An fMRI study of bilingual picture naming. Brain and language, 127, 452-462.

Linck, J. A., Kroll, J. F., \& Sunderman, G. (2009). Losing access to the native language while immersed in a second language: Evidence for the role of inhibition in second language learning. Psychological Science, 20, 1507-1515.

Lipski, J. M. (1978). Code-switching and the problem of bilingual competence. In M. Paradis (Ed.), Aspects of bilingualism (pp. 250-264). Columbus, SC: Hornbeam Press.

Litcofsky, K. A., \& Van Hell, J. G. (2017). Switching direction affects switching costs: Behavioral, ERP and time-frequency analyses of intra-sentential codeswitching. Neuropsychologia, 97, 112-139.

López, B. G., \& Vaid, J. (2018). Divergence and overlap in bilingual conceptual representation: Does prior language brokering experience matter? Bilingualism: Language and Cognition, 21, 150-161.

Lew-Williams, C., \& Fernald, A.(2007). Young children learning Spanish make rapid use of grammatical gender in spoken word recognition. Psychological Science, 18, 193-198.

MacDonald, M. C. (2013). How language production shapes language form and comprehension. Frontiers in Psychology, 4, 226.

MacDonald, M. C., \& Thornton, R. (2009). When language comprehension reflects production constraints: resolving ambiguities with the help of past experience. Memory \& Cognition, 37, 1177-1186.

Macizo, P., \& Bajo, M. T. (2006). Reading for repetition and reading for translation: Do they involve the same processes? Cognition, 99, 1-34.

Macizo, P., Bajo, T., \& Martín, M. C. (2010). Inhibitory processes in bilingual language comprehension: Evidence from Spanish-English interlexical homographs. Journal of Memory and Language, 63, 232-244.

Macnamara, J. (1967). The bilingual's linguistic performance-A psychological overview. Journal of Social Issues, 23, 58-77.

Macnamara, J., \& Kushnir, S. L. (1971). Linguistic independence of bilinguals: The input switch. Journal of Verbal Learning and Verbal Behavior, 10, 480-487. 
Macnamara, J., Krauthammer, M., \& Bolgar, M. (1968). Language switching in bilinguals as a function of stimulus and response uncertainty. Journal of Experimental Psychology, 78, 208-215.

Martín, M. C. (2010). Inhibitory control in bilingualism (Unpublished doctoral dissertation). University of Granada, Granada.

McNamara, B. N., \& Conway, A. R. A. (2015). Working memory capacity as a predictor of simultaneous language interpreting performance. Journal of Applied Research in Memory and Cognition, $5,434-444$.

Meuter, R. F. I., \& Allport, A. (1999). Bilingual language switching in naming: Asymmetrical costs of language selection. Journal of Memory and Language, 40, 25-40.

Misra, M., Guo, T., Bobb, S. C., \& Kroll, J. F. (2012). When bilinguals choose a single word to speak: Electrophysiological evidence for inhibition of the native language. Journal of Memory and Language, 67, 224-237.

Morales, J., Gómez-Ariza, C. J., \& Bajo, M. T. (2013). Dual mechanisms of cognitive control in bilinguals and monolinguals. Journal of Cognitive Psychology, 25, 531-546.

Morales, J., Padilla, F., Gómez-Ariza, C. J., \& Bajo, M. T. (2015). Simultaneous interpretation selectively influences working memory and attentional networks. Acta Psychologica, 155, $82-91$.

Morales, J., Yudes, C., Gómez-Ariza, C. J., \& Bajo, M. T. (2015). Bilingualism modulates dual mechanisms of cognitive control: Evidence from ERPs. Neuropsychologia, 66, 157-169.

Moreno, E. M., Federmeier, K. D., \& Kutas, M. (2002). Switching languages, switching palabras (words): An electrophysiological study of code switching. Brain and Language, 80, 188-207.

Muysken, P. (2000). Bilingual speech: A typology of code-mixing. Cambridge, UK: Cambridge University Press.

Myers-Scotton, C. (1993). Duelling languages: Grammatical structure in codeswitching. New York, NY: Oxford University Press.

Myslín, M., \& Levy, R. (2015). Code-switching and predictability of meaning in discourse. Language, 91, 871-905.

Otheguy, R., \& Lapidus, N. (2003). An adaptive approach to noun gender in New York contact Spanish. In R. Núñez-Cedeño \& R. Cameron (Eds.), A romance perspective on language knowledge and use (pp. 209-232). Amsterdam, The Netherlands: John Benjamins.

Padilla, F., Bajo, M. T., \& Macizo, P. (2005). Articulatory suppression in language interpretation: Working memory capacity, dual tasking and word knowledge. Bilingualism: Language and Cognition, 8, 207-219.

Pakulak, E., \& Neville, H. J. (2010). Proficiency differences in syntactic processing of monolingual native speakers indexed by event-related potentials. Journal of Cognitive Neuroscience, 22, 2728 2744.

Pfaff, C. W. (1979). Constraints on language mixing: Intrasentential code-switching and borrowing in Spanish/English. Language, 55, 291-318.

Piske, T., MacKay, I. R. A., \& Flege, J. E. (2001). Factors affecting the degree of foreign accent in an L2: A review. Journal of Phonetics, 29, 191-215.

Poplack, S. (1980). Sometimes I'll start a sentence in Spanish y termino en español: Toward a typology of code-switching. Linguistics, 18, 581-618.

Poplack, S. (2015). Code-switching (linguistic). In J. Wright (Ed.), International encyclopedia of the social and behavioral sciences (2nd ed., 918-925). Oxford, UK: Elsevier.

Reali, F., \& Christiansen, M. H. (2007). Word chunk frequencies affect the processing of pronominal object-relative clauses. Quarterly Journal of Experimental Psychology, 60, 161-170.

Roncaglia-Denissen, M. P., \& Kotz, S. A. (2016). What does neuroimaging tell us about morphosyntactic processing in the brain of second language learners? Bilingualism: Language and Cognition, 19, 665-673.

Ruiz, C., Paredes, N., Macizo, P., \& Bajo, M. T. (2008). Activation of lexical and syntactic target language properties in translation, Acta Psychologica, 128, 490-500.

Signorelli, T., Haarmann, H., \& Obler, L. (2011). Working memory in simultaneous interpreters: Effects of task and age. International Journal of Bilingualism, 16, 198-212.

Spivey-Knowlton, M., \& Sedivy, J. C. (1995). Resolving attachment ambiguities with multiple constraints. Cognition, 55, 227-267.

Steinhauer, K. (2014). Event-related potentials (ERPs) in second language research: A brief introduction to the technique, a selected review, and an invitation to reconsider critical periods in L2. Applied Linguistics, 35, 393-417. 
Stavrakaki, S., Megari, K., Kosmidis, M. H., Apostolidou, M., \& Takou, E. (2012). working memory and verbal fluency in simultaneous interpreters. Journal of Clinical and Experimental Neuropsychology, 34, 624-633.

Strobach, T., Becker, M., Schubert, T., \& Kühn, S. (2015). Better dual-task processing in simultaneous interpreters. Frontiers in Psychology, 6, 1-9.

Sunderman, G., \& Kroll, J. F. (2006). First language activation during second language lexical processing: An investigation of lexical form, meaning, and grammatical class. Studies in Second Language Acquisition, 28, 387-422.

Talamas, A., Kroll, J. F., \& Dufour, R. (1999). Form related errors in second language learning: A preliminary stage in the acquisition of L2 vocabulary. Bilingualism: Language and Cognition, 2, $45-58$.

Thomas, M. S. C., \& Allport, D. A. (2000). Language switching costs in bilingual visual word recognition. Journal of Memory and Language, 43, 44-66.

Timm, L. A. (1975). Spanish-English code switching: El porqué y how-not-to. Romance Philology, $28,473-482$.

Togato, G., Paredes, N., Macizo, P., \& Bajo, T. (2017). Syntactic processing in professional interpreters: Understanding ambiguous sentences in reading and translation. Applied Linguistics, 38, 581-598.

Torres Cacoullos, R., \& Travis, C. E. (2018). Bilingualism in the community: Codeswitching and grammars in contact. Cambridge, UK: Cambridge University Press.

Traxler, M. J., Morris, R., K., \& Seely, R. E. (2002). Processing subject and object relative clauses: Evidence from eye-movements. Journal of Memory and Language, 47, 69-90.

Treiman, R., Clifton, C. Jr., Meyer, A. S., \& Wurm, L. H. (2003). Language comprehension and production. In A. F. Healy \& R. W. Proctor (Eds.), Comprehensive handbook of psychology: Vol. 4, Experimental psychology (pp. 527-548). New York, NY: Wiley.

Trueswell, J. C., \& Kim, A. (1998). How to prune a garden path by nipping it in the bud: Fast priming of verb argument structure. Journal of Memory and Language, 39, 102-123.

Valdés Kroff, J. R. (2016). Mixed NPs in Spanish-English bilingual speech: Using a corpus based approach to inform models of sentence processing. In R. E. Guzzardo Tamargo, C. M. Mazak, \& M. C. Parafita Cuoto (Eds.), Spanish-English code-switching in the Caribbean and the US (pp. 281-300). Amsterdam, The Netherlands: John Benjamins.

Valdés Kroff, J. R., Dussias, P. E., Gerfen, C., Perrotti, L., \& Bajo, T. M. (2017). Experience with codeswitching modulates the use of grammatical gender during sentence processing. Linguistic Approaches to Bilingualism, 7, 163-198.

Van Hell, J. G., Litcofsky, K. A., \& Ting, C. Y. (2015). Sentential code-switching: Cognitive and neural approaches. In J. W. Schwieter (Ed.), The Cambridge handbook of bilingual processing (pp. 459-482). Cambridge, UK: Cambridge University Press.

Wicha, N. Y. Y., Moreno, E. M., \& Kutas, M. (2004). Anticipating words and their gender: An eventrelated brain potential study of semantic integration, gender expectancy, and gender agreement in Spanish sentence reading. Journal of Cognitive Neuroscience, 16, 1272-1288.

Yudes, C., Macizo, P., \& Bajo, M. T. (2012). Coordinating comprehension and production in simultaneous interpreters: Evidence from the articulatory suppression effect. Bilingualism: Language and Cognition, 15, 329-339.

Zhang, S., Morris, M. W., Cheng, C.-Y., \& Yap, A. Y. (2013). Heritage-culture images disrupt immigrants' second-language processing through triggering first-language interference. Proceedings of the National Academy of Sciences, 110, 11272-11277.

Zirnstein, M., Van Hell, J. G., \& Kroll, J. F. (2018). Cognitive control ability mediates prediction costs in monolinguals and bilinguals. Cognition, 176, 87-106. 